\title{
Repeated measurements are not better than initial measurement of Score for Neonatal Acute Physiology-II for prediction of in-hospital mortality in severely septic preterm neonates
}

\section{Rajendra Prasad Anne}

All India Institute of Medical Sciences

Venkataseshan Sundaram ( $\nabla$ venkatpgi@gmail.com )

Postgraduate Institute of Medical Education and Research https://orcid.org/0000-0002-3135-8115

\section{Praveen Kumar}

Post Graduate Institute of Medical Education and Research

\section{Research Article}

Keywords: preterm neonates, score for neonatal acute physiology-ll, serial measurements, linear mixed model, delta scores, mortality

Posted Date: May 5th, 2021

DOl: https://doi.org/10.21203/rs.3.rs-479108/v1

License: (c) (1) This work is licensed under a Creative Commons Attribution 4.0 International License.

Read Full License 


\section{Abstract}

The ability of serial versus single time application of 'Score for Neonatal Acute Physiology, version II' (SNAP-II) to predict mortality at day 14 in preterm neonates $<34$ weeks with severe sepsis was studied prospectively over 1-year in a tertiary care neonatal unit. SNAP-II scores were recorded at the onset of severe sepsis (T0) and serially at 24 (T1), 48 (T2) and 72 (T3) hours later. Delta scores ( $\triangle$ SNAP-II) were derived from the difference between any two SNAP-II scores. Seventy-one preterm neonates were enrolled. Baseline characteristics were similar in survivors $(n=53)$ and non-survivors $(n=18)$. Median SNAP-II scores at all the four time points were significantly higher in non-survivors $(p<0.001)$. The $\triangle$ SNAP-II (T0 - T2) score was significantly different between non-survivors and survivors (mean difference: -14.7; $95 \%$ Cl: -29, -0.9; $\mathrm{p}=0.02$ ), while the difference was not significant between T0 - T1 and T0 - T3. Initial SNAPII score had a significantly better discriminating ability for day 14 mortality (AUC (95\% C.I): 0.83 (0.70$0.93)$ ) than $\triangle$ SNAP-II scores at various time points (AUC (95\% C.I): $0.59(0.41-0.75)$ for T0 - T1, 0.70 $(0.50-0.87)$ for T0 - T2 and $0.64(0.38-0.89)$ for T0 - T3). Conclusion: Initial SNAP-II is better than $\Delta$ SNAP-II scores in predicting 14-day mortality in severely septic preterm neonates. Non-survivors had a significantly higher serial SNAP-II scores compared to survivors. Serial SNAP-II score do not have additional value in predicting mortality of preterm neonates with severe sepsis.

\section{Introduction}

Severity of illness scores predict outcomes including in-hospital mortality in adults as well as in the pediatric population [1, 2]. These scores were typically measured once at admission to the ICUs. Over the last two decades, studies done in adults and children have reported that serial measurements of these severity scores potentially improve the prediction of outcomes as change in the severity scores should reflect the change in the internal milieu better than a single time measurement. An increase in APACHE-II score from day 1 to day 3 in medical ICU predicting mortality in adults [3], increase in PELOD scores in a pediatric ICU from days 1 to 2 and 2 to 4 being associated with mortality [4], highest as well as mean SOFA scores predicting ICU mortality [5], maximum as well as delta scores of MODS, SOFA and LOD scores better predicting mortality [6] and an increase in severity scores significantly and variably preceded mortality in pediatric oncology patients [7], are all examples where change in serial severity scores were used for prediction of various outcomes.

A similar score called SNAP-II with six predictor variables was validated for NICU admissions [8, 9]. SNAPIl at admission to the NICU was reported to predict mortality in neonates with congenital diaphragmatic hernia [10]. Another study in severely septic preterm neonates reported that a SNAP-II of $\geq 40$, measured at the onset of severe sepsis, had a positive predictive value and specificity of $88 \%$ and $86 \%$, respectively, for mortality [11]. Serial measurements of SNAP-II did not live up to the expectations even though the available evidence is meagre to make such conclusions. Meadow et al showed that serial SNAP-II scores in premature neonates became progressively less helpful in distinguishing neonates who either died in the NICU or survived with low Mental/Psychomotor Developmental Index scores [12]. In another study, in neonates requiring mechanical ventilation, serial SNAP scores did not predict mortality, but admission 
SNAP scores did predict [13]. Severe sepsis/septic shock is one of the major causes for mortality in preterm neonates. The ability of serial measurements of SNAP-II scores in prediction of mortality in this population is very important but has not been studied yet. Hence, the current study was done in preterm neonates of $<34$ weeks' gestation with severe sepsis to assess whether a change in SNAP-II score over time can predict mortality by 14 days better in comparison to the initial SNAP-II score.

\section{Materials And Methods}

This prospective cohort study was conducted in the level III NICU of a tertiary care hospital in India. All consecutively inborn preterm neonates of $<34$ weeks' gestation and diagnosed to have septicemia with evidence of SIRS and OD were eligible for enrolment. Neonates with major congenital malformations, those who suffered severe perinatal asphyxia, who were moribund and those where parents refused for consent were excluded from the study. The study protocol was approved by the Institute Ethics Committee. An informed, written consent was obtained from one of the parents in all the enrolled subjects.

Septicemia was defined as presence of clinical signs of sepsis, with either blood culture or sepsis screen positive or with radiological evidence of pneumonia. Sepsis screen consisted of CRP, $\mu E S R, T L C, A N C$ and ITR of neutrophils. Sepsis screen was considered positive if $>2$ factors were abnormal. CRP $>10 \mathrm{mg} / \mathrm{L}$, $\mu \mathrm{ESR}>10 \mathrm{~mm}$ or 'age in days +3 ' $\mathrm{mm}$ in the first 7 days, TLC $<5000$ per $\mathrm{mm} 3$ and ITR above $20 \%$ were considered abnormal. ANC was assessed using Manroe's and Zipursky's charts [14, 15].

SIRS was defined based on the criteria framed by Adams-Chapman and the variables of temperature, respiratory rate, heart rate, blood pressure, and urine output were modified for preterm neonates [16]. Presence of at least 2 of the 4 criteria defined SIRS. Sever sepsis was defined as the presence of at least one $\mathrm{OD}$ in the 24-hour period preceding enrolment. OD criteria were adapted from a previous study done by Sundaram et al in severely septic preterm neonates [17].

SNAP-II score consisted of the following 6 parameters: 1) lowest mean arterial pressure, 2) worst ratio of partial pressure of oxygen ( $\mathrm{PaO} 2)$ to fraction of inspired oxygen, 3) lowest temperature $\left.\left({ }^{\circ} \mathrm{F}\right), 4\right)$ lowest serum $\mathrm{pH}, 5)$ occurrence of multiple seizures, and 6$)$ urine output $(<1 \mathrm{~mL} / \mathrm{kg} / \mathrm{hour})$. First 12 hours from the onset of severe sepsis served as the data collection window (T0) and scoring was repeated at 24 (T1), 48 (T2) and 72 (T3) hours from the first score. Delta scores ( $\triangle$ SNAP-II) were the difference in SNAP-II scores between two time points. Differences between T0 and T1 ( $\triangle$ SNAP-II_0-24), T0 and T2 ( $\triangle$ SNAPII_0-48) and T0 and T3 ( $\triangle$ SNAP-II_0-72) were used for analysis. The neonates were followed up to 14 days from the onset of severe sepsis or until remission from OD or death, whichever was earlier.

The study subjects were categorized into 2 groups- survivors by day 14 of enrollment and non-survivors. The ability of serial SNAP-II scores in predicting all-cause mortality by 14 days from the onset of severe sepsis was analyzed. We also compared the organ dysfunction status at the onset of severe sepsis and at 14 days or by death, whichever was earlier. 


\section{Sample size and statistical analysis}

In the unpublished annual data of the unit, a total of 80 neonates of $<34$ weeks' gestation developed severe sepsis and $60 \%$ of them died before discharge. With this data as baseline with an alpha error of $5 \%$, confidence level of $95 \%$ and accepting a variability of $5 \%$, a sample size of 65 was estimated. An additional $10 \%$ were recruited to account for attrition.

Normality of the numerical variables was assessed by the Kolmogorov-Smirnov test and Q-Q plots. Normally distributed numerical variables were compared by the Welch two-sample t-test whereas nonparametric variables were compared by the Wilcoxon Rank-Sum test. Categorical variables were compared for independence by the Pearson's Chi-squared test or by the Fisher's Exact test when the cell size of any one cell in the contingency table was $<5$. All SNAP-II scores were compared between the nonsurvivors and survivors. Total SNAP-II (sum of all scores), mean SNAP-II (average of all scores) and maximum SNAP-II (highest of the four scores) were calculated and compared between non-survivors and survivors. Bonferroni correction was done for multiple pairwise comparisons. Receiver-operating characteristic curves were generated for SNAP-II_0, SNAP-II_0-24, SNAP-II_0-48, SNAP-II_0-72, total SNAP-II, mean SNAP-II and maximum SNAP-II with mortality by day 14 and the generated AUROC curves were compared.

Considering the non-parametric distribution of SNAP-II with missing measurements at some time points and due to the correlated nature of the data due to repeated measurements of SNAP-II in same population at four different sequential time points, a linear mixed model analysis was carried out. In the model, 'SNAP-II' score was the response variable and 'time' (four time points of measurement) was the 'repeated measures' independent variable (model condition for within participant comparison) and outcome at day 14 (binomial categorical variable) was the independent variable. Both fixed effect (time and outcome at day 14) and random effects (subjects) were included in the model analysis. Contrasts were not used to break down the interactions as 'mortality by day 14' had only two levels. The effect sizes of the variables in the model were calculated as the product of their ' $t$ ' value and ' $d f$ ' (degrees of freedom). Post-hoc analysis for multiple comparisons was done by the 'tukey' method. A P value of $<0.05$ was considered as significant and the $95 \%$ confidence intervals were calculated by the 'bootstrap' method with 2000 repeated samplings with replacement and adequate adjustment for the correlated nature of the data. The R program and R packages "tidyverse", "nIme", "pastecs", "multcomp" and "ggplot2" were used for modelling [18-21] and for generating and comparing the ROC curves [22].

\section{Results}

Out of the 71 neonates included, 18 (25.4\%) died on or before 14 days from enrollment (Fig. 1). Demographic and baseline variables were comparable between non-survivors and survivors (Table 1). Seizures, shock and metabolic acidosis were more frequently observed in non-survivors. Apart from cardiovascular system dysfunction, other organ dysfunctions were not different between the studied groups (Table 2). 
Table 1

Comparison of baseline characteristics of the population

\begin{tabular}{|c|c|c|c|c|c|}
\hline S. & Variable & $\begin{array}{l}\begin{array}{l}\text { Non- } \\
\text { survivors } \\
(n=18) \\
\text { Mean (SD) }\end{array}\end{array}$ & $\begin{array}{l}\text { Survivors } \\
(\mathrm{n}=53) \\
\text { Mean } \\
(\mathrm{SD})\end{array}$ & $\begin{array}{l}\text { RR or MD } \\
\text { (95\% C.I) }\end{array}$ & $\mathbf{P}$ \\
\hline 1 & Gestational age (weeks) & $30.1(2.1)$ & $29.7(2.0)$ & $\begin{array}{l}0.4(-0.8 \\
1.5)\end{array}$ & $0.6^{a}$ \\
\hline 2 & Birth weight (grams) & $1118(321)$ & $\begin{array}{l}1155 \\
(265)\end{array}$ & $\begin{array}{l}37(-209 \\
136)\end{array}$ & $0.7^{a}$ \\
\hline 3 & Male gender & $12(67)$ & $28(53)$ & $1.6(0.7,3.7)$ & 0.5 \\
\hline 4 & Small for gestation & $8(44)$ & $33(62)$ & $0.6(0.3,1.3)$ & 0.3 \\
\hline 5 & Antenatal steroids & $12(67)$ & $44(83)$ & $0.5(0.2,1.2)$ & 0.3 \\
\hline 6 & PPROM & $10(56)$ & $26(49)$ & $1.2(0.5,2.7)$ & 0.8 \\
\hline 7 & Apgar at 1 minute & $4.4(2.9)$ & $5.5(2.8)$ & $\begin{array}{l}-1.1(-2.7 \\
0.5)\end{array}$ & $0.2^{b}$ \\
\hline 8 & Apgar at 5 minutes & $7.9(1.5)$ & $8(1.6)$ & $\begin{array}{l}-0.1(-0.9 \\
0.8)\end{array}$ & $0.9^{b}$ \\
\hline 9 & Received surfactant & $9(50)$ & $30(57)$ & $0.8(0.4,1.8)$ & 0.8 \\
\hline 10 & $\begin{array}{l}\text { Required respiratory support before } \\
\text { enrolment }\end{array}$ & $14(78)$ & $37(70)$ & $1.4(0.5,3.7)$ & 0.7 \\
\hline 11 & $\begin{array}{l}\text { Required invasive ventilation before } \\
\text { enrolment }\end{array}$ & $10(56)$ & $26(49)$ & $1.2(0.5,2.7)$ & 0.8 \\
\hline \multicolumn{6}{|c|}{$\begin{array}{l}\text { aWilcoxon Rank-Sum test, }{ }^{b} \text { Welch Two sample t-test, rest all were compared using Pearson's Chi- } \\
\text { squared test }\end{array}$} \\
\hline $\begin{array}{l}\text { Abb } \\
\text { PPR }\end{array}$ & $\begin{array}{l}\text { tions: SD- standard deviation, RR- ris } \\
\text { Preterm premature rupture of memb }\end{array}$ & MD- mean & rence, $\mathrm{Cl}-\mathrm{c}$ & fidence interv & \\
\hline
\end{tabular}


Table 2

Comparison of sepsis and organ dysfunction parameters across the groups

\begin{tabular}{|c|c|c|c|c|c|}
\hline $\begin{array}{l}\text { S. } \\
\text { No }\end{array}$ & Variable & $\begin{array}{l}\text { Non- } \\
\text { survivors } \\
(n=18) \\
\text { Mean } \\
\text { (SD) }\end{array}$ & $\begin{array}{l}\text { Survivors } \\
(\mathrm{n}=53) \\
\text { Mean } \\
(\mathrm{SD})\end{array}$ & $\begin{array}{l}\text { RR or MD } \\
(95 \% \text { C.I) }\end{array}$ & $\mathbf{P}$ \\
\hline 1 & Age at onset of sepsis (days) & $6.3(5.6)$ & $7.8(9.9)$ & $\begin{array}{l}-1.5(-5.3 \\
2.3)\end{array}$ & 0.4 \\
\hline 2 & Cardiovascular dysfunction at enrolment & $17(94)$ & $38(72)$ & $4.9(0.7,34)$ & 0.04 \\
\hline 3 & Respiratory dysfunction at enrolment & $8(44)$ & $21(40)$ & $1.2(0.5,2.6)$ & 0.7 \\
\hline 4 & Culture positive sepsis & $8(44)$ & $27(51)$ & $0.8(0.4,1.8)$ & 0.8 \\
\hline 5 & Sepsis due to GNB & $5 / 8(63)$ & $\begin{array}{l}22 / 27 \\
(81)\end{array}$ & $\begin{array}{l}0.5(0.14 \\
1.6)\end{array}$ & 0.3 \\
\hline \multirow[t]{8}{*}{6} & Clinical features of sepsis & $16(89)$ & $42(79)$ & $1.8(0.5,6.9)$ & 0.4 \\
\hline & - Respiratory distress & $4(22)$ & $2(4)$ & $3.1(1.5,6.4)$ & 0.04 \\
\hline & • Seizures & $8(44)$ & $17(32)$ & $1.5(0.7,3.3)$ & 0.4 \\
\hline & • Sclerema & $12(67)$ & $17(32)$ & $2.9(1.3,6.8)$ & 0.01 \\
\hline & • Shock & $17(94)$ & $35(65)$ & \multirow{3}{*}{$\begin{array}{l}6.2(0.9 \\
43.5) \\
0.5(0.2,1.6)\end{array}$} & 0.02 \\
\hline & - Metabolic acidosis & $3(17)$ & $17(32)$ & & 0.2 \\
\hline & • Neutropenia & \multirow{2}{*}{$2(11)$} & \multirow{2}{*}{$2(4)$} & & 0.3 \\
\hline & - Coagulopathy & & & $2.1(0.7,6.1)$ & \\
\hline 7 & CRP (mg/L) & $39(33)$ & $64(62)$ & $-25(-53,2.8)$ & 0.07 \\
\hline 8 & Absolute neutrophil count (per cubic mm) & $\begin{array}{l}9980 \\
(10225)\end{array}$ & $\begin{array}{l}6756 \\
(8550)\end{array}$ & $\begin{array}{l}3224 \\
(-2317 \\
8767)\end{array}$ & 0.2 \\
\hline 9 & $\begin{array}{l}\text { Total leukocyte count } \\
\text { (per cubic mm) }\end{array}$ & $\begin{array}{l}21750 \\
(16455)\end{array}$ & $\begin{array}{l}14996 \\
(13940)\end{array}$ & $\begin{array}{l}6754 \\
(-2155 \\
15662)\end{array}$ & 0.1 \\
\hline 10 & Platelet count (per cubic mm) & $\begin{array}{l}54000 \\
(25588)\end{array}$ & $\begin{array}{l}45204 \\
(26210)\end{array}$ & $\begin{array}{l}8796 \\
(-9680 \\
27272)\end{array}$ & 0.3 \\
\hline & $\begin{array}{l}\text { ations: SD- standard deviation, RR- risk ra } \\
\text { dysfunction, GNB - gram negative bacill } \\
\text { PaCO2- partial pressure of carbon dioxid }\end{array}$ & $\begin{array}{l}\text { MD- mear } \\
\text { RP- C-reac }\end{array}$ & $\begin{array}{l}\text { fference, } \\
\text { e protein, }\end{array}$ & $\begin{array}{l}\text { :onfidence int } \\
2 \text { - partial pres }\end{array}$ & $\begin{array}{l}\text { al, OD } \\
\text { re of }\end{array}$ \\
\hline
\end{tabular}




\begin{tabular}{|c|c|c|c|c|c|}
\hline $\begin{array}{l}\text { S. } \\
\text { No }\end{array}$ & Variable & $\begin{array}{l}\begin{array}{l}\text { Non- } \\
\text { survivors }\end{array} \\
(n=18) \\
\text { Mean } \\
\text { (SD) }\end{array}$ & $\begin{array}{l}\text { Survivors } \\
(\mathrm{n}=53) \\
\text { Mean } \\
(\mathrm{SD})\end{array}$ & $\begin{array}{l}\text { RR or MD } \\
(95 \% \text { C.I) }\end{array}$ & $P$ \\
\hline 11 & Blood pH & $\begin{array}{l}7.19 \\
(0.09)\end{array}$ & $7.26(0.1)$ & $\begin{array}{l}-0.07 \\
(-0.12,-0.001)\end{array}$ & 0.046 \\
\hline 12 & Base deficit & $-12.9(4.9)$ & $-9.5(2.6)$ & $3.4(0.8,6.0)$ & 0.01 \\
\hline 13 & $\mathrm{PaO} 2$ & $43.9(4)$ & $40.9(7.6)$ & $3.0(-3.3,8.9)$ & 0.3 \\
\hline 14 & $\mathrm{PaCO} 2$ & $58(11.5)$ & $65(8.5)$ & $-7.0(-81,67)$ & 0.6 \\
\hline 15 & $\begin{array}{l}\text { Presence of organ dysfunction at } \\
\text { enrolment } \\
\text { - Cardiovascular } \\
\text { - Respiratory } \\
\text { - Renal } \\
\text { - Hepatic } \\
\text { - Hematological }\end{array}$ & $\begin{array}{l}17(94) \\
8(44) \\
7(39) \\
1(6) \\
12(67)\end{array}$ & $\begin{array}{l}37(70) \\
21(43) \\
9(17) \\
3(6) \\
37(70)\end{array}$ & $\begin{array}{l}1.4(1.1,1.7) \\
1.1(0.6,2.1) \\
2.3(0.998 \\
5.3) \\
0.98(0.1 \\
8.9) \\
0.96(0.7 \\
1.4)\end{array}$ & $\begin{array}{l}0.034 \\
0.72 \\
0.055 \\
0.99 \\
0.80\end{array}$ \\
\hline 18 & $\begin{array}{l}\text { Presence of organ dysfunction at day } 14 \\
\text { of enrolment/death } \\
\text { - Cardiovascular } \\
\text { - Respiratory } \\
\text { - Renal } \\
\text { - Hepatic } \\
\text { - Hematological }\end{array}$ & $\begin{array}{l}18(100) \\
18(100) \\
18(100) \\
18(100) \\
18(100)\end{array}$ & $\begin{array}{l}1 \\
7\end{array}$ & $\begin{array}{l}53(7.6,369) \\
7.6(3.8,15) \\
26.5(6.8, \\
103) \\
105(6.7 \\
1661) \\
7.6(3.8,15)\end{array}$ & \\
\hline 19 & $\begin{array}{l}\text { Number of organs dysfunctional at } \\
\text { enrolment (mean, SD) }\end{array}$ & $2.5 \pm 0.99$ & $\begin{array}{l}2.06 \pm \\
0.77\end{array}$ & $\begin{array}{l}0.44(-0.007 \\
0.89)\end{array}$ & 0.054 \\
\hline
\end{tabular}

The initial SNAP-II scores as well as subsequent SNAP-II scores measured at 24, 48 and 72 hours from the onset of severe sepsis were significantly higher in non-survivors (Table 3 ). The mean, maximum and total SNAP-II scores were also significantly higher in non-survivors (Table 3). The $\triangle$ SNAP-II_0-48 score was significantly different between non-survivors and survivors (MD (95\% C.I): -14.7 (-29, -0.9); $p=0.02)$, whereas other $\triangle$ SNAP-II scores were similar (Table 3). 
Table 3

Comparison of SNAP-II assessments at various time points between survivors and non-survivors.

\begin{tabular}{|c|c|c|c|c|c|}
\hline \multirow[t]{2}{*}{ S. No } & \multirow[t]{2}{*}{ Parameter } & \multirow{2}{*}{$\begin{array}{l}\text { Non-survivors } \\
(n=18) \\
\text { Mean (SD) }\end{array}$} & \multirow{2}{*}{$\begin{array}{l}\text { Survivors } \\
(n=53) \\
\text { Mean (SD) }\end{array}$} & \multirow[t]{2}{*}{$\mathrm{MD}(95 \% \mathrm{Cl})$} & \multirow[t]{2}{*}{$\mathbf{P}$} \\
\hline & & & & & \\
\hline 1 & SNAP-II_0 & $29.6(17.1)$ & $11(11.9)$ & $18.6(9.5,27.5)$ & $<0.001$ \\
\hline 2 & SNAP-II_24 & $30(24.3)$ & $6.4(7.2)$ & $23.6(11,36.3)$ & $<0.001$ \\
\hline 3 & SNAP-II_48 & $36.4(24.5)$ & $5.2(7)$ & $31.2(17,45.3)$ & $<0.001$ \\
\hline 4 & SNAP-II_72 & $37(26)$ & $3.5(4.9)$ & $33.5(13.6,54)$ & $<0.001$ \\
\hline 5 & Total SNAP-II & $105(62.5)$ & $26.2(23.6)$ & $78.8(47,110)$ & $<0.001$ \\
\hline 6 & Mean SNAP-II & $33.1(19.6)$ & $6.5(5.9)$ & $26.6(16.7,36.4)$ & $<0.001$ \\
\hline 7 & Maximum SNAP-II & $45.8(24.5)$ & $13.5(11.5)$ & $32.3(19.8,44.8)$ & $<0.001$ \\
\hline 8 & Delta SNAP-II_0-24 & $-1.5(18.9)$ & $4.7(11)$ & $-6.2(-16.5,4.1)$ & 0.27 \\
\hline 9 & Delta SNAP-II_0-48 & $-8.8(23)$ & $5.9(12)$ & $-14.7(-29,-0.9)$ & 0.02 \\
\hline 10 & Delta SNAP-II_0-72 & $-5(25)$ & $7.6(11)$ & $-12.6(-31,6.1)$ & 0.15 \\
\hline \multicolumn{6}{|l|}{ Note: } \\
\hline \multicolumn{6}{|c|}{ a) Total SNAP-II - sum total of SNAP measured at four sequential time points } \\
\hline \multicolumn{6}{|c|}{ b) Mean SNAP-II - mean or average of the SNAP measured at four sequential time points } \\
\hline \multicolumn{6}{|c|}{ c) Maximum SNAP-II - highest/worst SNAP amongst the four sequential time points } \\
\hline $\begin{array}{l}\text { Abbre } \\
\text { mean }\end{array}$ & $\begin{array}{l}\text { ons: SNAP-II - Scor } \\
\text { erence, Cl- confiden }\end{array}$ & $\begin{array}{l}\text { ieonatal acute } \\
\text { rval }\end{array}$ & iology vers & SD- standard & n, MD - \\
\hline
\end{tabular}

Repeated SNAP-II measurements were analyzed by the linear mixed effects model. There was a significant main effect of the 'time' variable (time points when the SNAP-II was repeated) indicating that the change in SNAP-II score over time was significant in both the study groups $\left(\mathrm{Chi}^{2}(2)=6.22, \mathrm{p}=0.01\right)$. Similarly, there was a significant main effect of 'mortality by day 14' variable indicating that SNAP-II scores were significantly different between survivors and non-survivors irrespective of time $\left(\mathrm{Chi}^{2}(2)=\right.$ 55.46, $\mathrm{p}<0.0001)$. However, a significant interaction effect was observed between 'time' and 'mortality by day $14^{\prime}\left(\mathrm{Chi}^{2}(2)=24.89, \mathrm{p}<0.0001\right)$ indicating that the change in SNAP-II score over time is significantly different in non-survivors in comparison to survivors. The effect sizes of 'time', 'mortality by day 14' and 'time: mortality by day 14 ' interaction in the mixed model were $0.25,0.55$ and 0.35 , respectively, indicating the percentage of variability explained by each one of them. 
SNAP-II scores measured at all the four time points had good discriminatory ability for the primary outcome of death by 14 days (Table 4 \& Online resource 2). SNAP II score at 72 hours had an AUROC of 0.92 (95\% Cl: 0.81-0.99). However, the time points after the initial SNAP-Il had lesser study subjects due to mortality occurring before the next measurement. Total SNAP-II, mean SNAP-II and maximum SNAP-II had AUROC ( $95 \%$ C.I) of $0.86(0.73-0.96), 0.90(0.80-0.98)$ and $0.86(0.75-0.96)$, respectively, indicating an excellent ability of these summarized SNAP-II parameters to discriminate non-survivors from survivors (Table 4). Discriminatory ability of $\triangle$ SNAP-II scores ranged from poor to average (Table 4). On comparing the AUROC curves in a pairwise fashion with the initial SNAP-II as the primary comparator and after making necessary adjustments for the correlated nature of the comparisons, mean SNAP-II had an AUROC significantly better than the initial SNAP-II (Table 4).

Table 4

Discriminatory ability of various SNAP-II parameters

\begin{tabular}{|llll|}
\hline S. No & SNAP parameters & AUROC & $(95 \%$ C.I) \\
\hline 1 & SNAP-II_0 & 0.83 & $0.70-0.93$ \\
\hline 2 & SNAP-II_24 & 0.84 & $0.71-0.95$ \\
\hline 3 & SNAP-II_48 & 0.89 & $0.76-0.98$ \\
\hline 5 & SNAP-II_72 & 0.92 & $0.81-0.99$ \\
\hline 6 & SNAP-II_0-24 & 0.59 & $0.41-0.75$ \\
\hline 7 & SNAP-II_0-48 & 0.70 & $0.50-0.87$ \\
\hline 1 & SNAP-II_0-72 & 0.64 & $0.38-0.89$ \\
\hline 2 & Comparison parameters & AUROC & P \\
\hline 3 & SNAP-II_0 versus SNAP-II_0-24 & 0.83 vs. 0.59 & 0.05 \\
\hline 4 & SNAP-II_0 versus SNAP-II_0-48 & 0.83 vs. 0.70 & 0.18 \\
\hline 5 & SNAP-II_0 versus SNAP-II_0-72 & 0.83 vs. 0.64 & 0.19 \\
\hline 6 & SNAP-II_0 versus mean SNAP-II & 0.83 vs. 0.90 & 0.03 \\
\hline $\begin{array}{l}\text { a } 95 \% \text { confidence intervals were estimated by correlated boot strap estimation with } 2000 \text { resampling } \\
\text { repeats }\end{array}$ & SNAP-II_0 versus total SNAP-II & 0.83 vs. 0.86 & 0.4 \\
\hline $\begin{array}{l}\text { Abbreviations: AUROC - area under the receiver operating characteristic, SNAP-II - score for neonatal } \\
\text { acute physiology version 2, C.I - confidence intervals }\end{array}$ & & 0.4 \\
\hline
\end{tabular}

\section{Discussion}


Serial measurement of severity of illness scoring systems such as APACHE II, SOFA and MODS have been studied in adults and pediatric age groups and have shown that a change in the score between two or more time points preceded and predicted mortality [3-5]. Despite sepsis being one of the most common causes of neonatal mortality, such serial measurements of severity scores for a better prediction of risk of mortality in this population has not been studied till now. The key observations in the current study are: (i) SNAP-II scores measured at the onset of severe sepsis and at 24,48 , and 72 hours from the onset were significantly higher in non-survivors in comparison to survivors; (ii) the initial SNAP-Il score was statistically better than the $\triangle$ SNAP-II scores in discriminating non-survivors from survivors; (iii) the trend of SNAP-II scores was significantly different without any overlap between survivors and non-survivors.

A previous study done by the same authors reported a significantly higher median SNAP-II at the onset of severe sepsis in neonates who died in comparison to those who survived: median (IQR) $43(36,53)$ vs 18 $(16,37)$, respectively, $p<0.001$ [11]. An Egyptian study done in neonates with sepsis reported a significantly higher median SNAP-II score in those who died or developed OD [23]. Another study from Nepal reported that a SNAP-II score of $\geq 12$ predicted mortality with a sensitivity of $76 \%$ and specificity of $73 \%$ amongst all neonates admitted to NICU [24]. Any severity scoring system should preferably include the time factor so as to encompass the sequential changes that take place in the organ dysfunction. This is important as the illness and associated organ dysfunctions are not static and evolve over time. None of the above studies repeated the SNAP-II scores to assess the change.

Change in the severity score (delta scores) reflects disease progression as well as therapeutic response and facilitates therapeutic decision making. Adult studies in ICU's have demonstrated and validated the usefulness of delta scores in prognosticating mortality [25]. We observed that $\triangle$ SNAP-II_0-48, although significantly higher in non-survivors, had an average discriminative ability (AUROC: 0.70 ). This is similar to the observations made by Frain et al, where the ability of serial SNAP-II scores to predict mortality in neonates requiring mechanical ventilation decreased with time [13]. A systematic review on serial severity scores in neonates showed that in majority of the studies, SNAP-II scores were done only at admission to ICU and were used to predict mortality on first day of life. In the same analysis, 6 studies used them at later time points and 2 studies used the score in a prospective fashion. However, none of the studies included in the review tested the utility of serial measurements of SNAP-II scores, nor the population included a significant number of sick preterm neonates [26].

Maximum SNAP-II, total SNAP-II and mean SNAP-II scores are all summarized forms of the score which eventually reflects cumulative severity of the illnesses. Total and mean score capture the average degree of illness severity whereas maximum score captures the worst point in the course of the illness. Mean scores have a built-in denominator component and hence may get influenced by the number of observations, while the maximum score has the advantage of not being much affected by missing data points. In the current study, initial, total and maximum SNAP-II scores had similar AUROC curves, although AUROC curve of mean SNAP-II scores was statistically better than that of initial SNAP-II. Ferreira et al analyzed the association between initial, highest, total and mean SOFA scores and ICU mortality and reported that the mean SOFA score and highest SOFA score had the strongest association with mortality 
and highest SOFA score had the largest AUROC curve of 0.90 [5]. They also reported that the AUROC curve of highest SOFA was significantly larger in comparison to initial SOFA at admission to the ICU. Moreno et al reported that maximum SOFA score represented the cumulative organ dysfunction experienced by a patient and had a strong correlation with mortality outcome [27]. The findings in our study indicate that the initial SNAP-II score might perform similar to various cumulative measures of SNAP-II and better than delta SNAP-II scores in sick and septic preterm neonatal population. This observation of poor association between serial SNAP-II assessment and mortality needs further exploration in a larger population.

The current study has few limitations. Firstly, we did not evaluate other important outcomes such as length of hospital stays and survival without major morbidities. Secondly, the proportional contribution of individual SNAP-II parameters in prediction and prognostication were not analyzed. Despite these limitations, this is the first study of its kind in preterm neonates with severe sepsis which has examined the utility of sequential assessment of SNAP-II in comparison to initial SNAP-II using a robust linear mixed model analysis.

\section{Conclusions}

Serial measurements of SNAP-II scores were significantly higher in non-survivors compared to survivors. Initial SNAP-II score is better than $\triangle$ SNAP-II scores in discriminating non-survivors from survivors in this population. Mean SNAP-II score had a statistically better AUROC curve than the initial SNAP-II. However, cumulative scores have the disadvantage of the need for repeated assessments. Larger, multi-centric studies are needed to explore and answer the association between sequential SNAP-II assessments and mortality and its generalizability.

\section{Abbreviations}

APACHE- acute physiology and chronic health evaluation

ANC- absolute neutrophil count

AUROC- area under receiver operator characteristic

CRP- C-reactive protein

ICU- intensive care unit

ITR- immature to total ratio

LOD- logistic organ dysfunction

MAP- mean arterial pressure 
MODS- multiorgan dysfunction score

NICU- neonatal intensive care unit

OD- organ dysfunction

PELOD- pediatric logistic organ dysfunction

ROC- receiver operator characteristic

SIRS- systemic inflammatory response syndrome

SNAP- score for neonatal acute physiology

SOFA- sequential organ failure assessment

TLC- total leukocyte count

$\mu E S R$ - micro erythrocyte sedimentation rate

\section{Declarations}

Acknowledgements: None

\section{Funding and/or Conflicts of interests / competing interests}

The authors did not receive support from any organization for the submitted work.

The authors have no financial or non-financial interests to disclose

\section{Ethics approval}

This study was performed in line with the principles of the 1964 Declaration of Helsinki and its later amendments or comparable ethical standards. The study was approved by the Institute Ethics Committee of the study Institute

\section{Consent to participate and/or consent to publish}

Informed consent was obtained from the parents. Consent to publish is not applicable in this case

\section{References}

1. Ridley S (1998) Severity of illness scoring systems and performance appraisal. Anaesthesia 53:1185-94. https://doi.org/10.1046/j.1365-2044.1998.00615.x

2. Lacroix J, Cotting J, Pediatric Acute Lung Injury and Sepsis Investigators (PALISI) Network (2005) Severity of illness and organ dysfunction scoring in children. Pediatr Crit Care Med 6:S126-34. 
https://doi.org/ 10.1097/01.PCC.0000161287.61028.D4

3. Gartman EJ, Casserly BP, Martin D, Ward NS (2009) Using serial severity scores to predict death in ICU patients: a validation study and review of the literature. Curr Opin Crit Care 15:578-82. https://doi.org/ 10.1097/MCC.0b013e328332f50c

4. Leteurtre S, Duhamel A, Grandbastien B, et al (2010) Daily estimation of the severity of multiple organ dysfunction syndrome in critically ill children. CMAJ 182:1181-7. https://doi.org/ 10.1503/cmaj.081715

5. Ferreira FL, Bota DP, Bross A, Mélot C, Vincent JL (2001) Serial evaluation of the SOFA score to predict outcome in critically ill patients. JAMA 286:1754-8. https://doi.org/

10.1001/jama.286.14.1754

6. Khwannimit B (2008) Serial evaluation of the MODS, SOFA and LOD scores to predict ICU mortality in mixed critically ill patients. J Med Assoc Thai 91:1336-42.

7. Schneider DT, Cho J, Laws HJ, Dilloo D, Göbel U, Nürnberger W (2002) Serial evaluation of the oncological pediatric risk of mortality (O-PRISM) score following allogeneic bone marrow transplantation in children. Bone Marrow Transplant 29:383-9. https://doi.org/ 10.1038/sj.bmt.1703384

8. Richardson DK, Gray JE, McCormick MC, Workman K, Goldmann DA (1993) Score for Neonatal Acute Physiology: a physiologic severity index for neonatal intensive care. Pediatrics 91:617-23.

9. Richardson DK, Corcoran JD, Escobar GJ, Lee SK (2001) SNAP-II and SNAPPE-II: Simplified newborn illness severity and mortality risk scores. J Pediatr 138:92-100. https://doi.org/ $10.1067 / \mathrm{mpd} .2001 .109608$

10. Skarsgard ED, MacNab YC, Qiu Z, Little R, Lee SK, Canadian Neonatal Network (2005) SNAP-II predicts mortality among infants with congenital diaphragmatic hernia. J Perinatol 25:315-9. https://doi.org/ 10.1038/sj.jp.7211257

11. Sundaram V, Dutta S, Ahluwalia J, Narang A (2009) Score for neonatal acute physiology II predicts mortality and persistent organ dysfunction in neonates with severe septicemia. Indian Pediatr 46:775-80.

12. Meadow W, Lagatta J, Andrews B, et al (2008) Just, in time: ethical implications of serial predictions of death and morbidity for ventilated premature infants. Pediatrics 121:732-40. https://doi.org/ 10.1542/peds.2006-2797

13. Frain L, Soneji S, Ren Y, Yoon G, Bobila K, Kapustka H, Grant B, Lantos J, Meadow W (1998) Usefulness of Serial Algorithms of Illness Severity as a Proxy for Impending Death in the NICU: Not Much. Pediatr Res 43:29.

14. Manroe BL, Weinberg AG, Rosenfeld CR, Browne R (1979) The neonatal blood count in health and disease. I. Reference values for neutrophilic cells. J Pediatr 95:89-98. https://doi.org/ 10.1016/s0022-3476(79)80096-7

15. Zipursky A, Palko J, Milner R, Akenzua GI (1976) The hematology of bacterial infections in premature infants. Pediatrics 57:839-53. 
16. Adams-Chapman I, Stoll BJ (2001) Systemic inflammatory response syndrome. Semin Pediatr Infect Dis 12:5-16. https://doi.org/ 10.1053/spid.2001.19230

17. Venkataseshan S, Dutta S, Ahluwalia J, Narang A (2007) Low plasma protein C values predict mortality in low birth weight neonates with septicemia. Pediatr Infect Dis J 26:684-8. https://doi.org/ 10.1097/INF.0b013e3180f616f0

18. R Core Team (2020) R: A language and environment for statistical computing. R Found Stat Comput Vienna Austria. https://www.R-project.org/. Accessed on 27 April 2021.

19. Pinheiro J, Bates D, DebRoy S, Sarkar D, R Core Team (2021) nlme: Linear and nonlinear mixed effects models. R Package Version 31-152. https://CRAN.R project.org/package=nlme. Accessed on 27 April 2021.

20. Wickham H, Averick M, Bryan J, et al (2019) Welcome to the Tidyverse. J Open Source Softw 4:1686. https://doi.org/10.21105/joss.01686

21. Hothorn T, Bretz F, Westfall P (2008) Simultaneous inference in general parametric models. Biom J 50:346-63. https://doi.org/ 10.1002/bimj.200810425

22. Robin X, Turck N, Hainard A, Tiberti N, Lisacek F, Sanchez JC, Müller M (2011) pROC: an open-source package for R and $\mathrm{S}+$ to analyze and compare ROC curves. BMC Bioinformatics 12:77. https://doi.org/ 10.1186/1471-2105-12-77

23. Helal NF, Samra NM, Abdel Ghamy E, Said E (2013) Can the Score for Neonatal Acute Physiology II (SNAPII) Predict Morbidity and Mortality in Neonates with Sepsis. J Neonatal Biol 2:121. https://doi.org/ 10.4172/2167-0897.1000121

24. Shrestha D, Dhoubhadel BG, Parry CM, Prajapati B, Ariyoshi K, Mahaseth C (2017) Predicting deaths in a resource-limited neonatal intensive care unit in Nepal. Trans R Soc Trop Med Hyg 111:287-93. https://doi.org/ 10.1093/trstmh/trx053

25. Goldhill DR, Sumner A (1998) Outcome of intensive care patients in a group of British intensive care units. Crit Care Med 26:1337-45. https://doi.org/

26. Morse S, Groer M, Shelton MM, Maguire D, Ashmeade T (2015) A Systematic Review: The Utility of the Revised Version of the Score for Neonatal Acute Physiology Among Critically III Neonates. J Perinat Neonatal Nurs 29:315-44. https://doi.org/ 10.1097/00003246-199808000-00017

27. Moreno R, Vincent JL, Matos R, et al (1999) The use of maximum SOFA score to quantify organ dysfunction/failure in intensive care. Results of a prospective, multicentre study. Working Group on Sepsis related Problems of the ESICM. Intensive Care Med 25:686-96. https://doi.org/ $10.1007 / \mathrm{s} 001340050931$

\section{Figures}




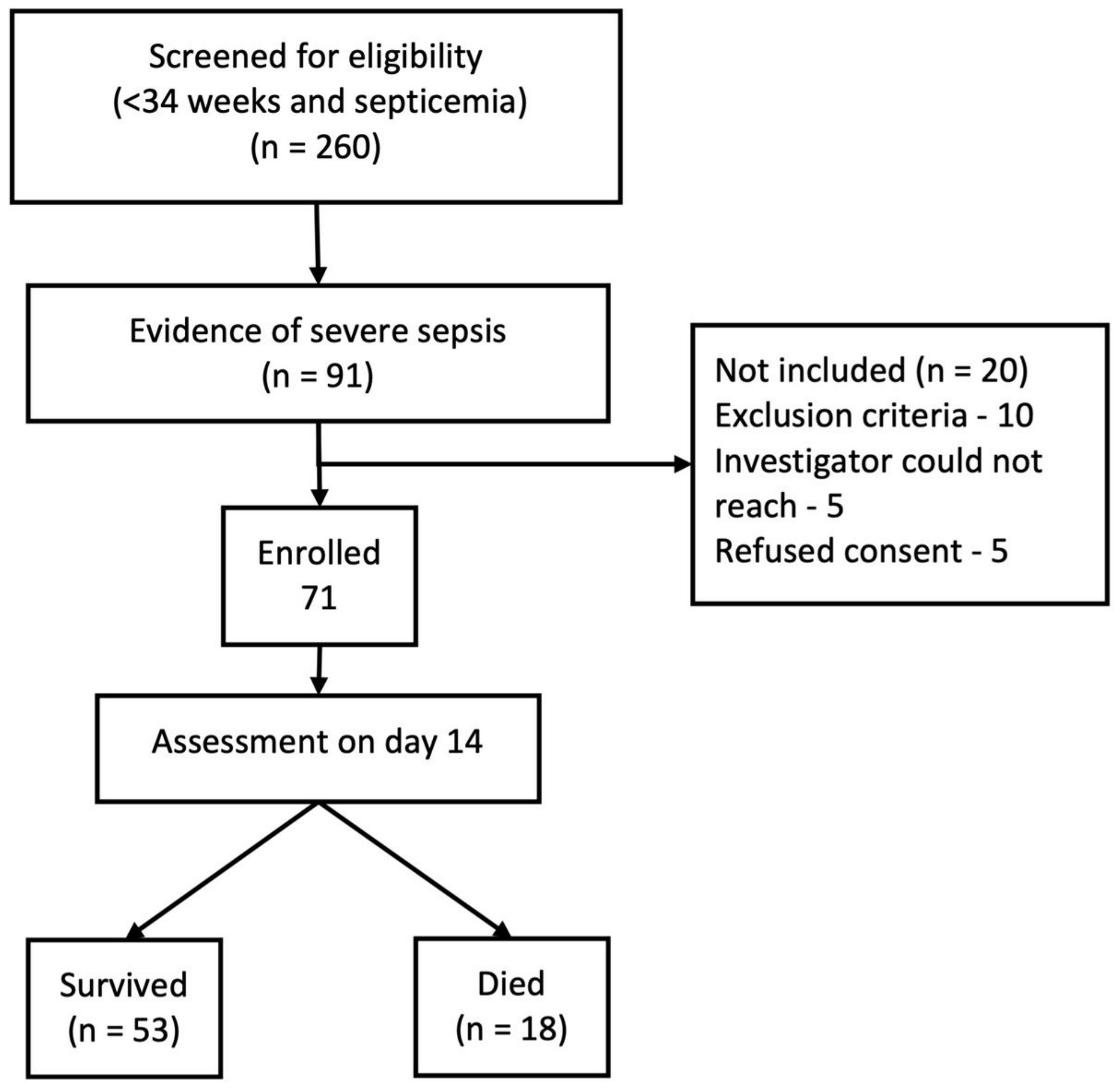

Figure 1

Participant flow chart 